University of Wisconsin Milwaukee

UWM Digital Commons

School of Information Studies Faculty Articles

Information Studies (School of)

Summer 7-2011

\title{
The Influence of Effects and Phenomena on Citations: A Comparative Analysis of Four Citation Perspectives
}

Qiang Wu

University of Science and Technology of China, qiangwu@ustc.edu.cn

Dietmar Wolfram

University of Wisconsin - Milwaukee School of Information Studies, dwolfram@uwm.edu

Follow this and additional works at: https://dc.uwm.edu/sois_facpubs

Part of the Scholarly Communication Commons, and the Scholarly Publishing Commons

\section{Recommended Citation}

Wu, Qiang and Wolfram, Dietmar, "The Influence of Effects and Phenomena on Citations: A Comparative Analysis of Four Citation Perspectives" (2011). School of Information Studies Faculty Articles. 3.

https://dc.uwm.edu/sois_facpubs/3 
This is a pre-print of the following article: Wu, Q., \& Wolfram, D. (2011). The influence of effects and phenomena on citations: A comparative analysis of four citation perspectives. Scientometrics, 89(1), 245258. The final publication is available at Springer via http://dx.doi.org/10.1007/s11192-011-0456-0.

The Influence of Effects and Phenomena on Citations:

A Comparative Analysis of Four Citation Perspectives

\author{
Qiang $\mathrm{Wu}^{1,2^{*}}$ and Dietmar Wolfram ${ }^{2^{*}}$ \\ 1. School of Management, University of Science and Technology of China \\ 96 Jinzhai Road, Hefei 230026, P. R. China \\ 2. School of Information Studies, University of Wisconsin-Milwaukee \\ P.O. Box 413, Milwaukee, WI U.S.A. 53201
}

\begin{abstract}
This article defines different perspectives for citations and introduces four concepts: Self-expected Citations, Received Citations, Expected Citations, and Deserved Citations. When comparing permutations of these four classes of perspectives, there are up to 145 kinds of equality/inequality relations. From these numerous relations, we analyze the difference between the Matthew Effect and the Matthew Phenomenon. We provide a precise definition and point out that many previous empirical research studies on the Matthew Effect based on citations belong primarily to the Matthew Phenomenon, and not the true meaning of the Matthew Effect. Due to the difficulty in determining the Deserved Citations, the Matthew Effect is in itself difficult to measure, although it is commonly believed to influence citation counts. Furthermore, from the theoretical facts, we outline four new effects/phenomena: the Self-confidence Effect/Phenomenon, the Narcissus Effect/Phenomenon, the Other-confidence Effect/Phenomenon, and the Flattery Effect/Phenomenon, and we discuss additional influencing factors.
\end{abstract}

Keywords: Citation analysis, Matthew Effect, Scholarly communication

*Both authors serve as corresponding authors. E-mail: qiangwu@ustc.edu.cn, (Q. Wu), dwolfram@uwm.edu (D. Wolfram).

Telephone: 001414229 4707. Fax: 0014142296699 


\section{Introduction}

A citation can be thought of as a token that is used to assess the influence of a given entity (e.g., author, group, publication). Generally, the higher the number of citations received by an entity, the more influential that entity is concluded to be. The uniform treatment of citations and how they are counted has long been criticized because of different factors that are recognized to influence citation behavior, and ultimately citation counts. These factors include the motivation of the citer (Garfield 1962; Smith 1981; Brooks 1985; MacRoberts and MacRoberts 1989; White and Wang 1997; Bornmann and Daniel 2008), the varying degrees of influence of the cited work which determines whether it is cited, and the social connections between citers and those being cited (White, Wellman and Nazer 2004). Viewing citations from another vantage point, Cozzens (1989) has argued that instead of being viewed as a form of reward, citations should be viewed as a form of rhetoric. In fact, citation behavior is very complex, which can be regarded as a culture (Wouters1999). There are many elements that can influence citation behavior so that "an individual is often partly unconscious of, or fails to recognize, his or her reasons for citing a particular source and not citing another" (Nicolaisen 2007).

Despite long recognized limitations of citations, citation counts continue to represent an important measure of research influence. They can also reflect the value of achievements in scientific research, but the value may be assessed differently by different researchers or disciplines. The purpose of this paper is to outline issues that affect the assessment of research and to draw attention to effects that ultimately influence citation counts. The authors identify additional effects and question whether what is observed and measured truly represent "effects" or if they represent "phenomena" that serve as representations of the effects.

\section{Effects and Their Influence on Citations}

An effect as it relates to citation analysis is any influencing factor that may change the number of citations an entity such as an author, workgroup, institution, or publication receives. The most well-known effect is the Matthew Effect outlined by Merton $(1968,1988)$. On the Matthew Effect in the field of citation analysis, Merton (1968) pointed out that "one can examine citation indexes to find whether in multiple discoveries by scientists of markedly unequal rank it is indeed the case that work published by the scientists 
of higher rank is the more promptly and more widely cited" (p.62). Here, he had affiliated the cause into the Matthew Effect, but he did not give a clear description about the meaning of "higher rank." Since then, nearly all scholars who have studied the Matthew Effect have also examined what causes the Matthew Effect. The effects may be influenced by the stature of the author receiving the citations (which in part is determined by the earlier number of citations received by the author), or other factors such as the prestige of the author's affiliation, which causes the author to receive more citations than warranted. Gaston (1978) proposed an opposite effect influenced by location, which he named the Podunk Effect, where the number of citations received is less than the number of citations truly deserved based on the affiliation of the author. The term Podunk has been used in American society to describe a small, backwater community. Gaston argued that authors affiliated with small, unrecognized institutions suffer from lower citation counts simply because of their affiliation. He went on to speculate about the possibility of other opposite effects such as the Knudop Effect (Podunk spelled backwards) to indicate higher than deserved recognition based on institutional affiliation or the Wehttam Effect, where authors from high-prestige affiliations receive low recognition (see also The KNUDOP Search Group 2008). Like the institutional affiliation of the author, this bias can extend to the national level, where authors from some countries are more likely to cited (Bonitz, Bruckner, and Scharnhorst 1997, 1999; Bonitz 2002). van Dalen and Henkens (2001) similarly noted the influence of demography on citations. This perceptual advantage conceivably also extends to specific journals, where an article appearing in a prestigious journal with a high journal impact factor may be cited more than if it appeared in a lower prestige journal (Judge, Cable, Colbert and Rynes 2007). This disparity in citations has also been argued to extend to gender. Rossiter (1993) outlined the Matthew-Matilda Effect, where the number of citations received is less than those deserved due to gender, with female authors being disadvantaged.

\section{Four Perspectives on Citations and Their Relationships}

Because citations represent, in a sense, a value of a given work, this value may vary depending on the perspective taken. This value of a published piece of research may be viewed from four perspectives:

\section{Self-expected Citations}

An author may have an expectation regarding the number of citations a given work will receive (selfexpectation) in a certain period of time. Authors may be confident or modest about their research and its 
impact, which may cause them to underestimate, overestimate or accurately estimate the number of citations their work will receive. Generally, authors are in the best position to understand the true value of their work more than their peers, but because of various psychological influences, their judgments are unlikely to be completely impartial and accurate. In the face of significant competition for university faculty recruitment, promotion and tenure, they may unconsciously overestimate themselves and underestimate their competitors.

\section{Received Citations}

Received citations represent the actual number of citations received by a given work in a certain period of time. The number of citations received may or may not reflect the true value of the research. Language barriers, limited accessibility of the publication source, and poor indexing or inclusion by databases can cause a work to go unrecognized and, therefore, be undercited.

\section{Expected Citations}

The expected number of citations represents the research community's assessment of the number of citations a given work warrants. This number may be more or less than the Received Citations. It is not a new idea, but may be interpreted in different ways. For example, Bonitz, Bruckner and Scharnhorst use journal impact factors (1999) and the so-called Matthew Effect for Countries (1997) to estimate the number of expected citations. Rehn, Kronman and Wadskog (2007) apply "field-normalized" indicators to determine the Expected Citations through the analysis of the fields. It can be measured, but may still reflect bias in research assessment based on the research community's inability to recognize the true value of a work. Also, this assessment may change over time and be influenced by future recognition. This change is exemplified in the idea of a "sleeping beauty" (van Raan 2004), where there is a delayed realization by the research community of the value of given research. Another example is the "flash in the pan" publication (van Dalen and Henkens 2005), in which a paper is quickly cited after publication but is quickly ignored thereafter. In contrast, the perceived value of a piece of research by the community may decline over time if there is a delayed recognition of the overestimated value of the research, whether through the discovery of errors or misconduct. Once a citation is given, however, it is difficult to take back. And even if the cited research has been retracted, citations may continue to accrue to the cited work because citing authors may be unaware of the retraction (Budd, Sievert, Schultz and Scoville 1999).

\section{Deserved Citations}

This represents an ideal that is free of any bias or error in assessment. Deserved citations may not be 
objectively measurable, so Received or Expected Citations usually serve as a proxy. Deserved Citations are different than the expected number of citations because the Expected Citation value is determined by a community, the members of which may also have their inherent biases that inflate or undervalue the value of the paper. As will be outlined below, it is "phenomena" that influence Expected Citation values and ideals or "effects" that influence Deserved Citations.

A parity or equivalence between Expected and Deserved Citations may only be realized long after the research is published. It is also possible that the Expected Citations may never reach the number of Deserved Citations, or may exceed the Deserved Citations if the overestimated value of the research is never realized. The numbers for each type of citation may change over time based on external factors such as how new research affects how existing research is viewed over time. In practice, when assessing research the Received Citations serve as the estimated value or influence of the publication. Other effects may affect the number of citations received and the resulting disparity in values between different citation perspectives. Ideally, each of the perspectives should be equal, where:

Self-expected Citations $=$ Received Citations $=$ Expected Citations $=$ Deserved Citations

Here, the author's judgment is equivalent to the actual number of citations, and also equal to the measurement determined by other indicators and the Deserved Citations. If the Deserved Citations can be thought as a true indicator of the quality of a paper, then the Received Citations truly reflects the quality or value of a paper and this evaluation also reflects the recognition of the authors and the academic community.

The reality is that each " $=$ " is likely to become " $>$ " or " $<$ " due to the influence of different effects. The four perspectives can be compared together, or as groups of two or three.

First, look at the results by comparing two selected perspectives. Three relations exist between any two of the four perspectives above. For example, there are three relations between the Received Citations and the Deserved Citations:

- Received Citations $=$ Deserved Citations - which reflects the objective relationship between citations and quality.

- Received Citations > Deserved Citations - this is the basic condition that leads to the Matthew Effect or Knudop Effect. 
- $\quad$ Received Citations < Deserved Citations - this is the basic condition that leads to the Podunk Effect or Wehttam Effect.

There are 18 relations that arise from comparing two perspectives, shown in Table 1.

Table 1 The 18 kinds of relationships between the two selected perspectives

\begin{tabular}{|l|l|}
\hline \multicolumn{1}{|c|}{ Type } & \multicolumn{1}{|c|}{ Expression } \\
\hline $\begin{array}{l}\text { The relationship between Self-expected } \\
\text { Citations and Received Citations }\end{array}$ & $\begin{array}{l}\text { Self-expected Citations }>\text { Received Citations } \\
\text { Self-expected Citations = Received Citations } \\
\text { Self-expected Citations < Received Citations }\end{array}$ \\
\hline $\begin{array}{l}\text { The relationship between Self-expected } \\
\text { Citations and Expected Citations }\end{array}$ & $\begin{array}{l}\text { Self-expected Citations }>\text { Expected Citations } \\
\text { Self-expected Citations = Expected Citations } \\
\text { Self-expected Citations < Expected Citations }\end{array}$ \\
\hline $\begin{array}{l}\text { The relationship between Self-expected } \\
\text { Citations and Deserved Citations }\end{array}$ & $\begin{array}{l}\text { Self-expected Citations }>\text { Deserved Citations } \\
\text { Self-expected Citations = Deserved Citations } \\
\text { Self-expected Citations < Deserved Citations }\end{array}$ \\
\hline $\begin{array}{l}\text { The relationship between Received } \\
\text { Citations and Expected Citations }\end{array}$ & $\begin{array}{l}\text { Received Citations }>\text { Expected Citations } \\
\text { Received Citations = Expected Citations } \\
\text { Received Citations < Expected Citations }\end{array}$ \\
\hline $\begin{array}{l}\text { The relationship between Received } \\
\text { Citations and Deserved Citations }\end{array}$ & $\begin{array}{l}\text { Received Citations }>\text { Deserved Citations } \\
\text { Received Citations = Deserved Citations } \\
\text { Received Citations < Deserved Citations }\end{array}$ \\
\hline $\begin{array}{l}\text { The relationship between Expected } \\
\text { Citations and Deserved Citations }\end{array}$ & $\begin{array}{l}\text { Expected Citations }>\text { Deserved Citations } \\
\text { Expected Citations }=\text { Deserved Citations } \\
\text { Expected Citations }<\text { Deserved Citations }\end{array}$ \\
\hline
\end{tabular}

Second, for three perspectives, there are 13 combinations, resulting in 52 kinds of relations (see Appendix 1). Here, the relations among the Self-expected Citations, the Received Citations and the Deserved Citations are as follows:

- Deserved Citations > Received Citations > Self-expected Citations

- Deserved Citations > Self-expected Citations = Received Citations

- Deserved Citations $>$ Self-expected Citations $>$ Received Citations

- Received Citations $=$ Deserved Citations $>$ Self-expected Citations

- Received Citations > Deserved Citations > Self-expected Citations

- Received Citations $>$ Self-expected Citations = Deserved Citations

- Received Citations > Self-expected Citations > Deserved Citations

- Self-expected Citations $=$ Deserved Citations $>$ Received Citations

- Self-expected Citations $=$ Received Citations $=$ Deserved Citations

- Self-expected Citations $=$ Received Citations $>$ Deserved Citations

- Self-expected Citations > Deserved Citations > Received Citations

- Self-expected Citations $>$ Received Citations $=$ Deserved Citations 
- Self-expected Citations > Received Citations > Deserved Citations

Finally, if comparing all four perspectives directly, there will be 75 kinds of relations, shown in Appendix 2. The ideal equation listed above is one of them. "Self-expected Citations $>$ Received Citations $>$ Expected Citations > Deserved Citations" and "Self-expected Citations < Received Citations $<$ Expected Citations $<$ Deserved Citations" are the other two relationships with a single symbol relationship.

In summary, there are a total of $145=18+52+75$ kinds of relationships shown. Therefore, the relationships among these four perspectives are very complex, and some relationships warrant special attention such as the Matthew Effect and the four new effects proposed by this paper.

Matthew Effect and Phenomenon

The Matthew Effect was first applied to the field of citation analysis due to its definition. In subsequent studies, some concepts derived from the Matthew Effect were proposed, such as the Podunk Effect, Wehttam Effect, Knudop Effect, and so on. But, in the end, we lost the uniform standard to define what the Matthew Effect itself is.

In addition to the four basic perspectives defined above, this paper also presents a new complete definition of Matthew Effect when studying citations:

For the articles with high citations, the Matthew Effect exists when the number of Received Citations is greater than the number of Deserved Citations.

That is, as long as Received Citations > Deserved Citations, we believe that the Matthew Effect happens, regardless of the cause, whether based on the scientist's higher rank (Merton 1968), lower rank(Gaston 1978), country (Bonitz, Bruckner and Scharnhorst 1997, 1999), gender (Rossiter 1993), or higher citation counts, etc. The Matthew Effect defined by this paper, however, does not search for its causes (or for that of the Knudop Effect). If we could further identify the causes, we may name them as the Matthew or Knudop Effect, which are caused by a specific reason (e.g. Matthew Effect caused by affiliation with a high ranking institute, Matthew Effect caused by author country of origin, Knudop Effect caused by a lower 
ranking journal, etc.) or XXX's Matthew or Knudop Effect (e.g. institution's Matthew Effect, country's Matthew Effect, journal's Knudop Effect, etc.).

The same applies to articles with low citations, where the Podunk Effect is observed (i.e., Received Citations < Deserved Citations), again not considering the cause. Unless the Deserved Citations can be actually found, the Matthew Effect will not be truly seen or understood.

To date there still are no clear findings regarding these effects, and the cases may never be found. So does the Matthew Effect actually exist? We believe it to exist as long as the citers pay more attention to the identity of the author, to the publication venue, or to the citations it receives, not to the paper itself. It is understood in theory to exist and can be accepted in practice, even without empirical proof. Although the Matthew Effect exists theoretically, measuring the effect is very difficult. The Matthew Effects obtained in practice are basically Matthew Phenomena, discussed below. In fact, the real Matthew Effect has not yet been proven with empirical cases. The reason for this is that we do not distinguish between the Expected Citations and the Deserved Citations.

Because the Deserved Citations are difficult to determine, we use the Expected Citations involuntarily as the Deserved Citations' alternative variable in the actual application. Some researchers have found that when Expected Citations > Received Citations, it is believed to be due to the influence of institutions, journals, scientists, countries, etc. However, these influencing factors may not be the reason. Actually, the high quality of the papers may have brought this discrepancy on their own because the papers published in higher impact journals usually are assumed to be of higher quality, the papers written by higher-rank scientists usually have the higher quality, and so on. At this time, the Received Citations may still be equal the Deserved Citations, although Received Citations > Expected Citations. Several papers have claimed that they had found the Matthew Effect to exist in citation analysis (Bonitz, Bruckner and Scharnhorst 1997, 1999; Bonitz 2002; Lariviere and Gingras 2010; Pislyakov and Dyachenko 2011; Petersen, Jung, Yang and Stanley2011), but according to our analysis, these do not encompass the true meaning of the Matthew Effect, but only the Matthew Phenomenon because their comparative objects are the Expected Citations, not the Deserved Citations. The authors of these studies did not distinguish between the Deserved Citations and the Expected Citations, but saw them as the same.

What is the Matthew Phenomenon? Similar to the definition of the Matthew Effect:

The Matthew Phenomenon exists when the number of Received Citations is greater than the 
number of Expected Citations.

As long as Received Citations > Expected Citations, we believe that the Matthew Phenomenon happens, regardless of the causes. After finding the XXX causes, we may call them the XXX's Matthew or Knudop Phenomenon. Furthermore, if Received Citations < Expected Citations, we can argue that a Podunk Phenomenon exists, but again without addressing the cause.

The difference between the Matthew Effect and Phenomenon can be seen more clearly in the following analysis based on a mathematical form.

\footnotetext{
Matthew Phenomenon's Citations $=$ Received Citations - Expected Citations (1)

Matthew Effect's Citations $=$ Received Citations - Deserved Citations (2)
}

Eq. 1 and 2 are the citations respectively attributable to the Matthew Phenomenon and the Matthew Effect. Subtracting the two equations, we have

Matthew Phenomenon's Citations - Matthew Effect's Citations $=$ Deserved Citations - Expected Citations (3)

Hence, from Eq. 3,

Matthew Phenomenon's Citations $=$ Matthew Effect's Citations $+($ Deserved Citations - Expected Citations) (4)

From Eq. 4, only when "Deserved Citations - Expected Citations" equals zero, (i.e. Expected Citations $=$ Deserved Citations) that is, when the Matthew Phenomenon's citations equals the Matthew Effect's citations, then we can think of the Matthew Phenomenon as being equivalent to the Matthew Effect. But the reality is that the Expected Citations may not be equal to the Deserved Citations, so we must separate the Matthew Phenomenon from the Matthew Effect. Generally, when the Matthew Phenomenon is found, the possibility of varying degrees of the Matthew Effect is great. From Eq. 1, at this time, the Received Citation can be broken down into two parts: one is the Matthew Effect's citations and the other the Deserved Citations. In short, the Matthew Phenomenon is valuable and can promote the further study of the existence of Matthew Effects. Of course, it should be a clear understanding of the Matthew Effect that is difficult to judge. Generally speaking, when the Matthew Phenomenon is detected in the area of citation analysis, some of the citations attributable to the paper's higher quality and other citations may be a result 
of the Matthew Effect.

Four New Types of Effects or Phenomenon

We may find the Matthew Effect by comparing the Received Citations with the Deserved Citations. If adding the authors' expectation about the citations of their papers to these comparisons, what new understanding can we gain? And what do we gain by investigating the authors' Self-expected Citations? In general, the authors are the researchers who are first convinced of their paper's quality and their selfestimations are usually valuable. For example, when supervisors direct and oversee the work of their postgraduate research students, they would like to let them read their own representative works as well as these works' major citations. As another example, when scholars introduce their achievements on a webpage, they often include their best works as their selected papers. Evidently, the authors make the judgments of their own papers all the time, especially in the period of time when their satisfactory papers are just published. They will be always concerned about the impact of these papers: they are very pleased to be cited by authorities, while dissatisfied with incorrect references, deliberate leakage of citations, and some neglected behavior. This paper can remind scientists to pay more attention to two facts: 1) on the one hand, one needs to be greatly concerned about the Self-expected Citations, because these selfjudgments are widespread, and; 2 ) on the other hand, one should also see the deviations in the numbers of citations which have been mainly reflected in four effects outlined below.

We have already outlined the relationships among the Self-expected Citations, Received Citations, and Deserved Citations, totaling 13 kinds listed above. If we omit the 3 relations based on "Self-expected Citations $=$ Received Citations", there are 10 relationships left. After combining some of the relationships, we can obtain four basic relationships, each relationship being given a new name, and representing the four new effects. These four new types of effects are as follows:

1. Self-confidence Effect: where Self-expected Citations $>$ Received Citations $<$ Deserved Citations. The author believes her/his paper achieves fewer citations than it apparently deserves, and this perception is correct. This effect can be further subdivided, including three specific situations as follows:

- $\quad$ Self-expected Citations $=$ Deserved Citations $>$ Received Citations

- $\quad$ Self-expected Citations $>$ Deserved Citations $>$ Received Citations

- $\quad$ Deserved Citations $>$ Self-expected Citations $>$ Received Citations 
2. Narcissus Effect: where Self-expected Citations $>$ Received Citations $\geq$ Deserved Citations. The author believes her/his paper achieves fewer citations than it apparently deserves, but this perception is wrong. It can be divided into two cases as follows:

- Self-expected Citations > Received Citations $>$ Deserved Citations

- Self-expected Citations $>$ Received Citations $=$ Deserved Citations

3. Other-confidence Effect: where Self-expected Citations $<$ Received Citations $\leq$ Deserved Citations. The author believes her/his paper achieves more citations than it apparently deserves, but this judgment is wrong. It can be divided into two cases as follows:

- Self-expected Citations $<$ Received Citations $<$ Deserved Citations

- Self-expected Citations $<$ Received Citations $=$ Deserved Citations

4. Flattery Effect: where Self-expected Citations $<$ Received Citations $>$ Deserved Citations.

The author believes her/his paper achieves more citations than it apparently deserves, and this understanding is right. This effect can be further subdivided, including three specific situations as follows:

- $\quad$ Received Citations $>$ Self-expected Citations $=$ Deserved Citations

- $\quad$ Received Citations $>$ Self-expected Citations $>$ Deserved Citations

- $\quad$ Received Citations $>$ Deserved Citations $>$ Self-expected Citations

As with the Matthew Effect, for which the deserved number of citations is difficult to determine, these four effects are also difficult to calculate in reality, although we believe that they exist and change the value of citation counts. When Expected Citations are used instead of Deserved Citations, we can get four corresponding phenomena as follows:

1. Self-confidence Phenomenon: where Self-expected Citations > Received Citations <Expected Citations. It includes three special cases:

- $\quad$ Self-expected Citations $=$ Expected Citations $>$ Received Citations

- $\quad$ Self-expected Citations $>$ Expected Citations $>$ Received Citations

- $\quad$ Expected Citations $>$ Self-expected Citations $>$ Received Citations

2. Narcissus Phenomenon: where Self-expected citations $>$ Received Citations $\geq$ Expected Citations. It can be divided into two cases:

- $\quad$ Self-expected Citations $>$ Received Citations $>$ Expected Citations

- $\quad$ Self-expected Citations $>$ Received Citations $=$ Expected Citations

3. Other-confidence Phenomenon: where Self-expected Citations < Received Citations $\leq$ Expected 
Citations. It includes two special cases:

- $\quad$ Self-expected Citations < Received Citations < Expected Citations

- $\quad$ Self-expected Citations $<$ Received Citations = Expected Citations

4. Flattery Phenomenon: Self-expected Citations < Received Citations $>$ Expected Citations. It can be further subdivided by three specific situations:

- $\quad$ Received Citations $>$ Self-expected Citations $=$ Expected Citations

- $\quad$ Received Citations > Self-expected Citations > Expected Citations

- $\quad$ Received Citations $>$ Expected Citations $>$ Self-expected Citations

These four phenomena can be found in the empirical analysis of citations and serve as proxies for their respective effects. Of course, we need to first investigate the authors' perspectives of their papers directly or obtain the information through other channels indirectly.

For example, many researchers would like to put their selected papers on their own webpage, but when compared to other comparable papers written by them, these papers are often not the most cited papers. At this time there may be an inconsistent understanding between the Received Citations and the Self-expected Citations. By then adding the Expected Citations, we can get the actual cases of these four phenomena. According to the definition advanced by this paper, we can deduce that the Matthew Phenomenon could only happen with the Narcissus Phenomenon or the Flattery Phenomenon, while the Podunk Phenomenon could only happen with the Self-confidence Phenomenon or the Other-confidence Phenomenon.

\section{Other Confounding Factors}

Whether considered as effects or phenomena the above influences are not the only ones that can affect citation counts. Some influencing factors arise from controllable means, such as the method used for counting citations. Others arise from additional perceptual effects that are more difficult to control.

The method for counting citations has been a longstanding area of investigation. Full citation counting provides full credit (i.e., one citation) for each author of a multi-authored publication. One could argue that citations to multi-authored works should be fractionally allocated based on the number of authors, or that only the first author receive a citation. In co-citation studies, limitations inherent in citation indexes may require that only first authors are considered unless investigators are willing to manually tabulate co- 
citation data for multi-authored works.

Co-authors may contribute differently to a given publication. To recognize the more significant contributions made by a given author, a greater fractional weight may be assigned to the first author or "fractional counting" to each author (Rousseau 1992; Egghe 1993, 2008). Different author ordering traditions makes this difficult to assess objectively. Authors may be listed alphabetically, based on contributions, or the most senior author could be listed last. There may be secondary influences by the above effects, where new authors receive the benefit of higher citations by collaborating with highly cited authors (i.e., riding the coattails of the more prominent author).

\section{Discussion and Further Research}

This study has focused on a theoretical analysis of citation relationships and research perceptions, but does not take an empirical approach. As there are many examples of the supposed Matthew Effect in practice, the four new effects proposed by the paper are also plentiful. However, since the Deserved Citations cannot be measured effectively, but the Expected Citations can be determined with some effort, we will observe a large number of studies investigating the Matthew Phenomena and also a great number of examples of the four new phenomena. We can only make continuous efforts to improve the measure of the Expected Citations, but it is almost impossible to accurately determine the Deserved Citations. The Deserved Citations, to some extent, can be viewed as a proxy for the quality of papers, but we can only easily measure the Received Citations. In the end, it may not be possible to determine what the total number the Deserved Citations will be.

Secondly, we choose the citation as a case to study the Matthew Effect and the other four new effects. The ideas presented here can be applied to the study of other areas, such as career success (Petersen, Jung, Yang and Stanley 2011). When equating citations to career-based measures, we can obtain four basic terms: the self-expected career position, the received career position, the expected career position, and the deserved career position. From this we can then estimate the career position's Matthew Effect or Matthew Phenomenon, and the career position's Self-confidence Effect/Phenomenon, Narcissus Effect/Phenomenon, Other-confidence Effect/Phenomenon, and Flattery Effect/Phenomenon. The Matthew Effect found by Petersen et al. (2011) was actually the Matthew Phenomenon, since there was insufficient evidence to prove "Expected Career Position = Deserved Career Position." 
Thirdly, the Self-expected Citations of co-authors may be different, which is another problem worthy of investigation. Why are the judgments by author A or by author B of the same paper not the same? Will the quantity of authors, the authorship, the contributions and the different areas influence the Selfexpected Citations? The author with a high contribution may overestimate the value of the paper due to her/his greater efforts. Conversely, the author who makes a small contribution may have a tendency to underestimate the quality of the paper.

Fourthly, there are many biases that can influence the number of citations a paper receives that are independent of the "quality" of the paper. The biases can be divided into two parts: systematic bias, and random bias. The systematic biases can be further subdivided into two parts: those caused by external factors, such as the publication year, the research field, the venue in which the paper appears, etc. Others are caused by psychological or personal factors, which are the effects or phenomena examined in this study. Because random biases happen casually and their influences are limited, our study doesn't include them. Of course, random biases may change with time. If there is evidence to indicate that the random biases happen regularly and are influential, they should be regarded as types of systematic biases which are the causes of the effects/phenomena.

There is great potential for these areas of research and, based on extensive and detailed study, we can recognize what citation counts do measure. After reducing the influence of various effects or phenomena, the citations can be amended to be closer to the true value of research. We must strive to close the gap between Expected Citations and Deserved Citations through rigorous peer review, finding more appropriate methods of evaluation, taking measures to reduce inappropriate references and so on. It is important to make Deserved Citations $=$ Received Citations, and to reduce the influence of the Matthew Effect and Podunk Effect to a minimum. Each author must be able to objectively evaluate the value of her/his research, so that Self-expected Citations $=$ Received Citations. The equation "Self-expected Citations $=$ Received Citations $=$ Expected Citations $=$ Deserved Citations" should be an ultimate goal by those who pursue the study of citation analysis.

\section{Acknowledgments}

This research was supported in part by National Natural Science Foundation of China (Project No. 70973117).We would also like to thank the reviewers for their helpful suggestions. 


\section{Appendix}

Table 2. The 52 kinds of relationships among the three selected perspectives

\begin{tabular}{|c|c|}
\hline Type & Expression \\
\hline $\begin{array}{l}\text { The relationship among Self-expected Citations, } \\
\text { Received Citations, and Expected Citations }\end{array}$ & $\begin{array}{l}\text { Self-expected Citations }>\text { Received Citations }>\text { Expected Citations } \\
\text { Self-expected Citations }>\text { Received Citations }=\text { Expected Citations } \\
\text { Self-expected Citations }>\text { Expected Citations }>\text { Received Citations } \\
\text { Received Citations }>\text { Self-expected Citations }>\text { Expected Citations } \\
\text { Received Citations }>\text { Self-expected Citations }=\text { Expected Citations } \\
\text { Received Citations }>\text { Expected Citations }>\text { Self-expected Citations } \\
\text { Expected Citations }>\text { Self-expected Citations }>\text { Received Citations } \\
\text { Expected Citations }>\text { Self-expected Citations }=\text { Received Citations } \\
\text { Expected Citations }>\text { Received Citations }>\text { Self-expected Citations } \\
\text { Self-expected Citations }=\text { Received Citations }>\text { Expected Citations } \\
\text { Self-expected Citations }=\text { Expected Citations }>\text { Received Citations } \\
\text { Received Citations }=\text { Expected Citations }>\text { Self-expected Citations } \\
\text { Self-expected Citations }=\text { Received Citations }=\text { Expected Citations }\end{array}$ \\
\hline $\begin{array}{l}\text { The relationship among Self-expected Citations, } \\
\text { Received Citations, and Deserved Citations }\end{array}$ & $\begin{array}{l}\text { Self-expected Citations }>\text { Received Citations }>\text { Deserved Citations } \\
\text { Self-expected Citations }>\text { Received Citations }=\text { Deserved Citations } \\
\text { Self-expected Citations }>\text { Deserved Citations }>\text { Received Citations } \\
\text { Received Citations }>\text { Self-expected Citations }>\text { Deserved Citations } \\
\text { Received Citations }>\text { Self-expected Citations }=\text { Deserved Citations } \\
\text { Received Citations }>\text { Deserved Citations }>\text { Self-expected Citations } \\
\text { Deserved Citations }>\text { Self-expected Citations }>\text { Received Citations } \\
\text { Deserved Citations }>\text { Self-expected Citations }=\text { Received Citations } \\
\text { Deserved Citations }>\text { Received Citations }>\text { Self-expected Citations } \\
\text { Self-expected Citations }=\text { Received Citations }>\text { Deserved Citations } \\
\text { Self-expected Citations }=\text { Deserved Citations }>\text { Received Citations } \\
\text { Received Citations }=\text { Deserved Citations }>\text { Self-expected Citations } \\
\text { Self-expected Citations }=\text { Received Citations }=\text { Deserved Citations }\end{array}$ \\
\hline $\begin{array}{l}\text { The relationship among Self-expected Citations, } \\
\text { Expected Citations, and Deserved Citations }\end{array}$ & $\begin{array}{l}\text { Self-expected Citations }>\text { Expected Citations }>\text { Deserved Citations } \\
\text { Self-expected Citations }>\text { Expected Citations }=\text { Deserved Citations } \\
\text { Self-expected Citations }>\text { Deserved Citations }>\text { Expected Citations } \\
\text { Expected Citations }>\text { Self-expected Citations }>\text { Deserved Citations } \\
\text { Expected Citations }>\text { Self-expected Citations }=\text { Deserved Citations } \\
\text { Expected Citations }>\text { Deserved Citations }>\text { Self-expected Citations } \\
\text { Deserved Citations }>\text { Self-expected Citations }>\text { Expected Citations } \\
\text { Deserved Citations }>\text { Self-expected Citations }=\text { Expected Citations } \\
\text { Deserved Citations }>\text { Expected Citations }>\text { Self-expected Citations } \\
\text { Self-expected Citations }=\text { Expected Citations }>\text { Deserved Citations } \\
\text { Self-expected Citations }=\text { Deserved Citations }>\text { Expected Citations } \\
\text { Expected Citations }=\text { Deserved Citations }>\text { Self-expected Citations } \\
\text { Self-expected Citations }=\text { Expected Citations }=\text { Deserved Citations }\end{array}$ \\
\hline $\begin{array}{l}\text { The relationship among Received Citations, } \\
\text { Expected Citations, and Deserved Citations }\end{array}$ & $\begin{array}{l}\text { Received Citations }>\text { Expected Citations }>\text { Deserved Citations } \\
\text { Received Citations }>\text { Expected Citations }=\text { Deserved Citations } \\
\text { Received Citations }>\text { Deserved Citations }>\text { Expected Citations } \\
\text { Expected Citations }>\text { Received Citations }>\text { Deserved Citations } \\
\text { Expected Citations }>\text { Received Citations }=\text { Deserved Citations } \\
\text { Expected Citations }>\text { Deserved Citations }>\text { Received Citations } \\
\text { Deserved Citations }>\text { Received Citations }>\text { Expected Citations } \\
\text { Deserved Citations }>\text { Received Citations }=\text { Expected Citations } \\
\text { Deserved Citations }>\text { Expected Citations }>\text { Received Citations } \\
\text { Received Citations }=\text { Expected Citations }>\text { Deserved Citations } \\
\text { Received Citations }=\text { Deserved Citations }>\text { Expected Citations } \\
\text { Expected Citations }=\text { Deserved Citations }>\text { Received Citations } \\
\text { Received Citations }=\text { Expected Citations }=\text { Deserved Citations }\end{array}$ \\
\hline
\end{tabular}


Table 3. The 75 kinds of relationships among the four perspectives

Self-expected Citations $>13$ kinds of relationships among Received Citations, Expected Citations, and Deserved Citations Received Citations $>13$ kinds of relationships among Self-expected Citations, Expected Citations, and Deserved Citations Expected Citations $>13$ kinds of relationships among Self-expected Citations, Received Citations, and Deserved Citations Deserved Citations $>13$ kinds of relationships among Self-expected Citations, Received Citations, and Expected Citations Self-expected Citations $=$ Received Citations $>3$ kinds of relationships between Expected Citations and Deserved Citations Self-expected Citations $=$ Expected Citations $>3$ kinds of relationships between Received Citations and Deserved Citations Self-expected Citations $=$ Deserved Citations $>3$ kinds of relationships between Received Citations and Expected Citations Received Citations = Deserved Citations $>3$ kinds of relationships between Self-expected Citations and Expected Citations Received Citations = Expected Citations $>3$ kinds of relationships between Self-expected Citations and Deserved Citations Expected Citations = Deserved Citations $>3$ kinds of relationships between Self-expected Citations and Received Citations Self-expected Citations $=$ Received Citations $=$ Expected Citations $>$ Deserved Citations Self-expected Citations $=$ Received Citations $=$ Deserved Citations $>$ Expected Citations Self-expected Citations $=$ Expected Citations $=$ Deserved Citations $>$ Received Citations Received Citations $=$ Expected Citations $=$ Deserved Citations $>$ Self-expected Citations Self-expected Citations $=$ Received Citations $=$ Expected Citations $=$ Deserved Citations

Note: All expressions of the 3 and 13 kinds of relationships were shown in Table 1 and Table 2, respectively. 


\section{References}

Bonitz, M., Bruckner, E., \& Scharnhorst, A. (1997).Characteristics and impact of the Matthew Effect for countries. Scientometrics, 40, 407-422.

Bonitz, M., Bruckner, E., \& Scharnhorst, A. (1999). The Matthew Index - concentration patterns and Matthew core journals. Scientometrics, 44, 361-378.

Bonitz, M. (2002). Ranking of nations and heightened competition in Matthew core journals: Two faces of the Matthew Effect for countries. Library Trends, 50(3), 440-460.

Bornmann, L., \& Daniel, H-D. (2008). What do citation counts measure? A review of studies on citing behavior. Journal of Documentation, 64(1), 45-80.

Brooks, T.A. (1985). Private acts and public objects: An investigation of citer motivations. Journal of the American Society for Information Science, 36, 223-229.

Budd, J.M., Sievert, M.E., Schultz, T.R., \& Scoville, C. (1999).Effects of article retraction on citation and practice in medicine. Bulletin of the Medical Library Association, 87(4), 437-443.

Cozzens, S.E. (1989). What do citations count? The rhetoric-first model. Scientometrics, 15,437-447.

Egghe, L. (1993). Consequences of Lotka's law in the case of fractional counting of authorship and of first author counts. Mathematical and Computer Modelling, 18 (9), 63-77.

Egghe, L. (2008).Mathematical theory of the h- and g-index in case of fractional counting of authorship. Journal of the American Society for Information Science and Technology, 59 (10), 1608-1616.

Garfield, E. (1962). Can citation indexing be automated? Essays of an Information Scientist, 1,84-90.

Gaston, J. (1978). The reward system in British and American science. New York: John Wiley \&Sons.

Judge, T.A., Cable, D.M., Colbert, A.E., \&Rynes, S.L. (2007). What causes a management article to be citedarticle, author, or journal? Academy of Management Journal, 50(3),491-506.

The KNUDOP Search Group (2008). Podunk Effect. ISSI Newsletter, 4(2), 23.

Lariviere, V., \& Gingras, Y. (2010). The impact factor's Matthew Effect: A natural experiment in bibliometrics. Journal of the American Society for Information Science and Technology, 61(2), 424-427.

MacRoberts, M. H., \& MacRoberts, B. R. (1989). Problems of citation analysis: A critical review. Journal of the American Society for Information Science, 40(5), 342-349.

Merton, R.K. (1968). The Matthew Effect in science. Science, 159, 56-63.

Merton, R.K. (1988). The Matthew Effect in science, II, ISIS, 79, 606-623. 
Nicolaisen, J. (2007). Citation analysis. Annual Review of Information Science and Technology, 41, 609-641. Petersen, A. M., Jung, W-S., Yang, J-S., \& Stanley, H. E. (2011).Quantitative and empirical demonstration of the Matthew Effect in a study of career longevity. Proceedings of the National Academy of Sciences of the United States of America, 108, 18-23.

Pislyakov, V., \& Dyachenko, E. (2011).Citation expectations: are they realized? Study of the Matthew index for Russian papers published abroad. Scientometrics, 83(3), 739-749.

Rehn, C., Kronman, U., \& Wadskog, D. (2007).Bibliometric indicators - definitions and usage at KarolinskaInstitutet. Stockholm, Sweden: Karolinska Institutet University Library.

Rossiter, M.W. (1993). The Matthew-Matilda effect in science. Social Studies in Science, 23, 325-341.

Rousseau, R. (1992). Breakdown of the robustness property of Lotka's law: The case of adjusted counts for multi-authorship attribution. Journal of the American Society for Information Science, 43(10), 645-647. Smith, L.C. (1981). Citation analysis. Library Trends, 30, 83-106.

van Dalen, H. P., \& Henkens, K. (2001). What makes a scientific article influential? Scientometrics, 50(3), 455-482.

van Dalen, H.P., \& Henkens, K. (2005). Signals in science - On the importance of signaling in gaining attention in Science. Scientometrics, 64(2), 209-233.

van Raan, A.F.J. (2004). Sleeping Beauties in science. Scientometrics, 59(3), 461-466.

White, M.D., \& Wang, P. (1997). A qualitative study of citing behavior: Contributions, criteria, and metalevel documentation concerns. Library Quarterly, 67, 122-154.

White, H.D., Wellman, B., \& Nazer, N. (2004). Does citation reflect social structure?: Longitudinal evidence from the "Globenet" interdisciplinary research group. Journal of the American Society for Information Science and Technology, 55, 111-126.

Wouters, P. (1999). The Citation Culture. Ph.D. Thesis, University of Amsterdam. 